\title{
A IMPORTÂNCIA DA LIBRAS NO PROCESSO DE INCLUSÃO SOCIAL DO CIDADÃO SURDO NO BRASIL: DA ESCOLARIZAÇÃO ATÉ O MERCADO DE TRABALHO
}

\section{${ }^{* 1}$ Dânlei de Oliveira Preato, ${ }^{2}$ Roseli Maria de Jesus Soares and ${ }^{3}$ Queila Barbosa Alves Druzian}

${ }^{1}$ Especialista em Docência no Ensino Superior pela, Faculdade de Pimenta Bueno - FAP, Jaru - RO, Brasil; ${ }^{2}$ Especialista em Didática do Ensino Superior pela, Faculdade de Ciências Biomédicas de Cacoal - FACIMED, Cacoal - RO, Brasil; ${ }^{3}$ Mestranda em Ensino de Ciências da Natureza pela, Unir-Universidade Federal de Rondônia, Cacoal - RO, Brasil

\section{ARTICLE INFO}

\section{Article History:}

Received $28^{\text {th }}$ March, 2020

Received in revised form

$17^{\text {th }}$ April, 2020

Accepted $20^{\text {th }}$ May, 2020

Published online $29^{\text {th }}$ June, 2020

\section{Key Words:}

Labor market, Deaf Student, Inclusion.

*Corresponding author: Dânlei de Oliveira Preato,

\begin{abstract}
This article clarifies the inclusion of deaf students in society, agreeing with the importance of this right, and thus, in a succinct way, highlights the legal bases that ensure the right from education to the labor market, defines what inclusion is, difficulties faced by deaf and / or deaf citizens in this process, exposing the importance of the school and the teacher in this process of social inclusion. The research was carried out through bibliographic surveys by means of true and legitimate documents. It is considerable nowadays, to defend that education is a right of all, and that it is ensured in the Federal Constitution, taking care not only to guarantee entry, but to structure it so that it remains and is successful in that school path, at different levels of education when it is known that Brazil has advanced in terms of the creation of laws, protection and protection for people with deafness.
\end{abstract}

Copyright (C) 2020, Dânlei de Oliveira Preato et al. This is an open access article distributed under the Creative Commons Attribution License, which permits unrestricted use, distribution, and reproduction in any medium, provided the original work is properly cited.

Citation: Dânlei de Oliveira Preato, Roseli Maria de Jesus Soares and Queila Barbosa Alves Druzian 2020. "A importância da libras no processo de inclusão social do cidadão surdo no brasil: da escolarização até o mercado de trabalho”, International Journal of Development Research, 10, (06), 36929-36934.

\section{INTRODUCTION}

Discorrer sobre o processo de inclusão social do surdo requer que seja debatido sobre Inclusão Escolar, o qual é de caráter mundial. Nesse contexto, o presente artigo tem como finalidade demonstrar o papel da escola, do professor, e do mercado de trabalho no processo de inclusão, trazendo o que tem que ser feito para que de fato essa inclusão ocorra. $\mathrm{O}$ trabalho inicia-se discorrendo sobre a inclusão escolar trazendo as bases legais que asseguraram a matrícula do aluno com necessidades especiais, a qual muitos gestores desconhecem e respondem sem respaldo legal diante da realidade. Para Ribas (2007, p 17) "embora se saiba que uma pessoa com deficiência tem o mesmo direito à educação, trabalho, segurança, saúde, etc. que os indivíduos sem deficiência, não estamos suficientemente instrumentalizados para garanti-los amplamente a todos". O artigo se embasa em revisão bibliográfica em livros, revistas, artigos, dissertações e teses, os quais debatem a mesma temática, com o objetivo de contrapor a realidade e pesquisas existentes, assim, busca soluções viáveis para resolver as barreiras e problemas enfrentados pelo surdo no processo de inclusão social, perante a sociedade.
Principais Leis e decretos que asseguram a inclusão no Brasil

A educação e atendimento especializado são regidos pela Lei magna do Brasil, a Constituição Federal do Brasil de 1988, no Capítulo III, da Educação, da Cultura e do Desporto, Seção I Da Educação, em seu artigo 208, define que o atendimento as pessoas com necessidades especiais deve ser dado, preferencialmente, na rede regular de ensino. "[...]. II - 208. O dever do Estado com a educação será efetivado mediante a garantia de: III - atendimento educacional especializado aos portadores de deficiência, preferencialmente na rede regular de ensino [...]". (BRASIL, 1988).

Na Lei de Diretrizes e Bases da Educação Nacional, LDB de 1996, o ensino especial é contemplado no capítulo V, nos Art. 58 e 59, os quais especificam esse apoio:

Art. 58. Entende-se por educação especial, para os efeitos desta Lei, a modalidade de educação escolar, oferecida preferencialmente na rede regular de ensino, para educandos portadores de necessidades especiais. 
§ $\mathbf{1}^{\mathbf{0}}$. Haverá, quando necessário, serviços de apoio especializado, na escola regular, para atender às peculiaridades da clientela de educação especial.

$\S \mathbf{2}^{\mathbf{0}}$. O atendimento educacional será feito em classes, escolas ou serviços especializados, sempre que, em função das condições específicas dos alunos, não for possível a sua integração nas classes comuns de ensino regular.

Art. 59. Os sistemas de ensino assegurarão aos educandos com necessidades especiais:

I - currículos, métodos, técnicas, recursos educativos e organização específicos, para atender às suas necessidades;

II - terminalidade específica para aqueles que não puderem atingir o nível exigido para a conclusão do ensino fundamental, em virtude de suas deficiências, e aceleração para concluir em menor tempo o programa escolar para os superdotados;

Essa citação traz em minucia o que trata a LDB, instruindo as instituições de como proceder quando se tem o aluno com deficiência e como prepara a escola e os professores para recebê-lo, buscando sempre melhorar a qualidade de ensino, nessa realidade a escola deve se enquadrar ao aluno e não o inverso, devendo ser respeitada a especialidade do aluno.

\section{Lei $n^{0} 8.112$ de 11 de dezembro de 1990 - provimento na Administração Pública Federal}

Diante do contexto capitalista em que vivemos, é que se dá à inserção do surdo no mercado de trabalho formal. Tendo sua maior representação com a aprovação da Lei $n^{\circ} 8.112$ de 11 de Dezembro de 1990, que garante o direito de pessoas com deficiência de se inscrever em concurso público tendo o direito assegurado de $20 \%$ das vagas, "cujas atribuições sejam compatíveis com a deficiência de que são portadoras" (PASTORE, 2000,47).
Art. 5 São requisitos básicos para investidura em cargo público:
§ 2 $2^{\mathbf{0}}$ Às pessoas portadoras de deficiência é assegurado o direito de se inscrever em concurso público para provimento de cargo cujas atribuições sejam compatíveis com a deficiência de que são portadoras; para tais pessoas serão reservadas até $20 \%$ (vinte por cento) das vagas oferecidas no concurso. (BRASIL, 1990).

O art $.5^{\mathbf{0}}$ faz referencia a distribuição de vagasnos concursos públicos, até $20 \%$ dos cargos vagos são reservados para pessoas com deficiência. Portanto, esse percentual não é o mesmo para cada estado, município ou distrito federal, uma vez que a lei de cada uma dessas instituições estabelece o percentual de taxas de admissão para pessoas com deficiência. Por exemplo, no estado de Rondônia, Constituição Estadual, art. $1^{\circ}$ e Lei $\mathrm{n}^{\circ} 515$, de 04 de outubro de 1993, esse percentual é de $10 \%$.

Art. $1^{\circ}$ - Fica reservado aos portadores de deficiências, o percentual de $10 \%$ (dez por cento) das vagas, por ocasião da realização de concursos públicos em qualquer órgão da administração direta e fundacional do Estado, inclusive dos Poderes Legislativo e Judiciário.

I - caso a aplicação do referido percentual resulte em número fracionado, este deverá ser elevado até o primeiro número inteiro subsequente, respeitado o limite máximo

\section{de $10 \%$ (dez por cento) das vagas ofertadas; (RONDÔNIA, 1993).}

As pessoas com deficiência têm preferência ante os demais, caso aprovado no concurso, independentemente de sua classificação. Caso nenhuma pessoa com deficiência seja aprovada em um concurso, desconsideram-se as vagas reservadas para eles. Mesmo tendo uma legislação Federal, na qual fixa uma porcentagem de vagas em concursos públicos, as pessoas com necessidades especiais, fica um tanto vago, deixando os governantes de cada Federação fixar um percentual de acordo com sua administração, variando assim tal percentual entre as Federações, uma, vez que a Lei Federal $8112 / 90$ ressalva que até $20 \%$ das vagas dos concursos deveram ser reservadas as pessoas com necessidades especiais, deste modo deixando cada Federação fixar este limite respeitando a Legislação Federal.

\section{Lei 8.213 de 24 de julho de 1991 - Lei de Cotas}

Propõe-se a adoção de legislação específica que discipline a reserva de mercado de trabalho para as pessoas com deficiência nas entidades do setor privado. Temos a disposição a Lei $n^{\circ} 8.213$ de julho de 1991 (BRASIL), que no artigo 93, obriga as empresas com 100 ou mais empregados, a preencher de $2 \%$ a $5 \%$ cargos com benefícios reabilitados ou pessoas com deficiências habilitadas, nas seguintes proporções:

Art. 93. A empresa com 100 (cem) ou mais empregados está obrigada a preencher de $2 \%$ (dois por cento) a $5 \%$ (cinco por cento) dos seus cargos com beneficiários reabilitados ou pessoas portadoras de deficiência, habilitadas, na seguinte proporção:

I - até 200 empregados ............................................2\%;

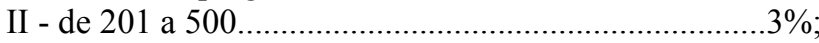

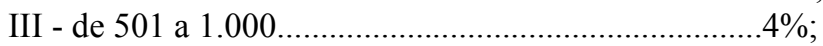

IV - de 1.001 em diante..............................................5\%.

(BRASIL, 1991).

A empresa que não respeitar essa lei corre o risco de ser multada, devido a fiscalizações realizadas pelo Ministério Público do Trabalho (MPT), por meio de auditores-fiscais (art. $36, \S 5^{\circ}$, do Decreto $\left.n^{\circ} 3.298 / 99\right)$. O valor destas infrações vai variar de acordo com o número de funcionários que a empresa mantém e o número de pessoas com deficiência que ela deixa de contratar:

I-para empresa com 100 a 200 empregados multiplicar-seá o número de trabalhadores portadores de deficiência ou beneficiários reabilitados que deixaram de ser contratados pelo valor mínimo legal, acrescido de zera a $20 \%$.

II - para empresas com 201 a 500 empregados, multiplicar-se-á o número de trabalhadores portadores de deficiência ou beneficiários reabilitados que deixaram de ser contratados pelo valor mínimo legal, acrescido 20 a $30 \%$.

III-para empresas com 501 a 1.000 empregados multiplicar-se-á o número de trabalhadores portadores de deficiência ou beneficiários reabilitados que deixara de ser contratados pelo valor mínimo legal, acrescido de 30 a $40 \%$.

IV-para empresas com mais de 1.000 empregados, multiplicar-se-á o número de trabalhadores portadores de deficiência ou beneficiários reabilitados que deixaram de 
ser contratados pelo valor mínimo legal, acrescido de 40 a $50 \%$.

$\S 1^{\circ} \mathrm{O}$ valor mínimo legal a que se referem o inciso I a IV deste artigo é o previsto no art. 133 da Lei $n^{\circ} 8.213$, de 1991.

§2 $2^{\circ}$ O valor resultante da aplicação dos parâmetros previstos neste artigo não poderá ultrapassar o máximo estabelecido no art.133 da Lei $n^{\circ} 8.213$, de 1991 (Portaria $\mathrm{n}^{\circ} 1.199$, de 28 de outubro de 2003)

$\mathrm{O}$ de acordo com artigo $10 \mathrm{~V}$ da Lei 8.213/91 determina valor mínimo da multa, sendo reajustado anualmente

I - de R\$ 1.195, 13 a 1.434,16 para empresas de 100 a 200 empregados;

II - de R\$ 1.434,16 a R\$ 1.553,67 para empresas de 201 a 500 empregados;

III - de R $\$ 1.553,67$ a $\mathrm{R} \$ 1.673,18$ para empresas de 501 a 1.000 empregados;

IV-de R\$ $1.673,18$ a $\mathrm{R} \$ 1.792,70$ para empresas com mais 1.000 empregados.

Nota-se, tal Lei foi um grande avanço no que tange a inclusão do Surdo ao mercado de trabalho, uma vez que em seu art. 93 obriga as empresas do setor privado, a contratar pessoas com necessidades especiais, tendo o risco da empresa ser atuada por auditores fiscais, em descumprimento de tal dispositivo legal.

\section{A Lei ${ }^{\circ} 10.436$ de 24 de abril de 2002 - Lei da Língua Brasileira de Sinais}

Reconhecida como lei da Libras, em seu artigo primeiro, a LIBRAS ganha status como meio de comunicação ou de expressão a ser utilizado pelas pessoas surdas, e no parágrafo único do mesmo, entende-se que a língua é dotada de recursos e estrutura gramatical e linguística própria. A comunidade surda que usam a LIBRAS persevera uma cultura peculiar a sua língua e luta de seus direitos. Demais artigos dessa lei tratam de garantir a acessibilidade do uso da LIBRAS e sua divulgação em todos os lugares públicos, como língua oficial das comunidades surdas do Brasil, permitindo ao cidadão com surdez o seu uso frequente nos diferentes ambientes, seja ele particular ou governamental. Destaque também, para obrigatoriedade da inclusão da disciplina de LIBRAS nos cursos superiores da educação e da saúde, de acordo, com os Parâmetros Curriculares Nacionais, que subsidiam a educação nacional.

\section{Disposições sobre o Decreto $n^{\circ} 5.626$ / 2005}

Esse decreto instituiu o uso e difusão da Língua Brasileira de Sinais (LIBRAS) -, como meio de comunicação e expressão das comunidades surdas, e oficializou Libras como disciplina obrigatória no curso de formação de professores, mas especificar-se-á alguns artigos que tratam diretamente sobre a temática do trabalho, que discorre sobre a educação dos surdos. Convêm destacar o Art. $14^{\circ}$ que explicita:

Art.14 ${ }^{\circ}$ As instituições federais de ensino devem garantir, obrigatoriamente, às pessoas surdas acesso à comunicação, à informação e à educação nos processos seletivos, nas atividades e nos conteúdos curriculares desenvolvidos em todos os níveis, etapas e modalidade de educação, desde a educação infantil até à superior.

$\$ 1^{\circ}$ Para garantir o atendimento educacional especializado e o acesso previsto no caput, as instituições federais de ensino devem: I- promover cursos de formação de professores para: a) o uso e o ensino da LIBRA; b) o ensino da LIBRA; c) o ensino da Língua Portuguesa, como segunda língua para as pessoas surdas; II- prover as escolas com: a) professor de LIBRAS ou instrutor de LIBRAS; b) tradutor e intérprete de LIBRAS-Língua Portuguesa .(BRASIL, 2005, p.2).

Como citado, é obrigatoriedade do Governo Federal garantir a acessibilidade de comunicação, informação e educação aos alunos surdos em todos os níveis escolares, independente de qual etapa ou modalidade de ensino estejam esses educandos. No parágrafo primeiro, inciso I explicita-se para que este atendimento especializado seja garantido é preciso antes que haja a formação de professores (por meio de uma capacitação) com o intuito de aprenderem a LIBRAS como um recurso linguístico, usual e didático para o ensino da mesma aos alunos com surdez, citados na alínea a, b e na alínea c e a contratação de docentes que ensinem prioritariamente a Língua Portuguesa na modalidade escrita, para os alunos surdos como sua segunda língua, já que a primeira língua do surdo é a LIBRAS. $\mathrm{O}$ inciso II complementa que a União, deve providenciar às escolas a contratação de professores que saibam a LIBRAS ou de instrutores que ensinem os alunos com surdez quando estes não souberem. Quando não houver um professor especializado que saiba a Língua Brasileira de Sinais, faz-se necessário, a presença de um intérprete de LIBRAS - Língua Portuguesa em sala de aula como meio eficaz para a interpretação do conteúdo curricular para o aluno com surdez (quando esses alunos já adquiriram a língua), além de professores que ensinem a Língua Portuguesa como segunda língua, que respeitem e reconheça a diferença linguística desses alunos.

Outro artigo a se destacar é o Art. $22^{\circ}$ faz referência à inclusão do aluno surdo, em seus incisos, valorizam as escolas ou classes bilíngues, que os professores que atendem a demanda escolar, saibam a Língua Portuguesa e, concomitantemente, a LIBRAS, para que possam interpretar para seus alunos surdos, seja na Educação Infantil ou Ensino Fundamental. Garante também que os educandos surdos tenham acesso e pleno direito quando não estão em classes ou escolas especiais de frequentarem em turno oposto de seu atendimento na escola regular, um atendimento especializado com um profissional especializado, a fim de complementar seu currículo escolar, por meio de recursos e equipamentos pedagógicos que possibilitem uma adequação curricular mais satisfatória para o seu desempenho escolar. Fundamentando a educação, tem-se o Art. $23^{\circ}$, o qual delega que da educação básica a educação superior é preciso dar subsídios ao aluno surdo, com o apoio de intérprete de LIBRAS em sala de aula e no ambiente que suscite um apoio educacional, bem como, acesso a equipamentos tecnológicos que visem o acesso às bibliografias referentes às características biopsicossociais e linguísticas do aluno surdo.

\section{A Lei Brasileira de Inclusão - LBI Nº13. 146/2015}

Essa lei busca garantir direitos das pessoas com deficiência em muitas áreas, tais como: lazer, cultura, trabalho, transporte, acessibilidade em geral. Em relação à educação os direitos centram-se na proibição de cobrança de taxas a mais dos pais dos alunos com deficiência, reserva de dez por cento das vagas à pessoas com deficiência nos cursos de graduação, pós graduação, educação profissional e tecnológica, tanto em instituições públicas e privadas, caso não há candidatos essas são estendidas aos demais participantes e reitera a obrigação 
de incluir no currículo de ensino superior, conteúdos que tratam dessa temática, bem como, criação de um núcleo cuide dessas especificações. Há discussões sobre o retrocesso em relação ao local de oferta do ensino ao aluno, antes dito que preferencialmente no ensino regular, ficando as escolas especiais somente com atendimento especializado, e com a nova redação, os centros especiais poderão ofertar os anos iniciais de escolarização, retrocesso porque voltará a ter a segregação (BRASIL, 2015).

\section{Inclusão Escolar}

O Brasil vem se destacando pelos avanços legais com finalidade de amparar e resguardar o direito dosalunos surdos e/ou com surdez no ensino regular, tendo a Constituição Federal de 1988 e Leis Educacionais que resguardam esse direito. A matrícula e a continuidade do discentecom necessidade especial,especialmente do aluno surdo no ensino regular brasileiro, não configuram por si só em inclusão escolar. $\mathrm{O}$ termo inclusão é derivado da palavra incluir, que se define como introduzir, já escolar é derivado de escola, cuja sua definição é estabelecimento onde se ensina. Partindo desse contexto, inclusão escolar é acolher de um modo generalizado, qualquer sujeito, sem restrição, de cor, nível social e aspectos físicos e psicológicos. Partindo desse pressuposto, Carvalho (2016) defende que os alunos surdos enfrentam grandes dificuldades na comunicação dentro das salas de aula, já que eles não entendem a escrita da língua portuguesa, assim como o aluno ouvinte desconhece a língua de sinais. Muitos professores também não têm conhecimento da língua de sinais para que possa de maneira fluída transmitir a explicação dos conteúdos explicados em sala de aula ao aluno surdo, comprometendo no processo de ensino e aprendizado desses educandos. Embora a inclusão escolar seja considerada como um mecanismo para se chegar de fato à inclusão social, fica evidente que tal fator não foi almejado nas escolas inclusivas, visto que na maioria das instituições de ensino regular do Brasil é constituído de professores e alunos ouvintes que não apresentam um domínio amplo e fluído da LIBRAS, ou até mesmo a desconhecem. Desse modo, a cultura surda é desconsiderada afetando o ensino e aprendizagem do discente, em que nas maiorias das escolas a cultura ouvinte é predominante.

Segundo Sassaka (2002) descreve que uma escola inclusiva procede, permanentemente, de mudanças em seu sistema, adaptando o ambiente escolar, readequando suas metodologias e capacitando seu corpo docente e demais funcionários da comunidade escolar, inclusive alunos e a sociedade em seu entorno para que de fato a escola seja inclusiva. Rechico e Marostega (2002, p.23) que ao defender a educação de surdos no ensino regular, evidencia várias dúvidas, incerteza se esse conhecimentodiferenciado é apto para introduzir no ambiente sem mudar o conceito dos ouvintes, ou se é mais uma experiência que está ligada à exclusão, por não compreender o surdo como uma minoria linguística.

Escolarização: Perfil da Escola e do Professor: A escola tem como função desenvolver recursos que auxiliam a inclusão do estudante surdo e/ou com surdez no seu espaço físico e pedagógico, desenvolvendoo Projeto Político Pedagógico (PPP) sem restrições desses alunos. Ao contrário, eles devem ser incluídos em suas pluralidades, bem como os objetivos a curto, médio e longo prazo que se quer atingir.
Discorrendo desse pressuposto Carvalho (2016) o Projeto Político Pedagógico deve trazer em seu desenvolvimento extensões culturais que apresentem os princípios filosóficos que conduzem a instauração dos objetivos a serem alcançadas, condições políticas para estruturação peculiar do ambiente escolar e aspectos práticos para elaborar habilidades pedagógicas em sala de aula, como procedimentos que sejam facilitadores do aluno, professores e pais que deles carecem. Em vista disso, uma escola que almeja um perfil inclusivo devem não apenas com as metodologias de ensino, mas também com o processo de capacitação e adaptação de seus professores e demais funcionários de seu ambiente, almeja desenvolver projetos nesse ambiente para mesclar toda escola em um princípio inclusivo, e o principal, planejará e valorizará o conhecimento do aluno nos aspectos: social, motor, cognitivo e afetivo, valorizando suas habilidades e competências, respeitando suas limitações. Segundo a Reily (2001) o professor tem um papel fundamental como mediador dos processos de ensino-aprendizagem numa escola inclusiva. Seu primeiro contato com o aluno surdo e/ou com surdez será primordial perante os demais alunos da sala, pois será através da atitude do professor perante essa necessidade que a sala irá vê-lo. Também compete ao professor organizar os trabalhos pedagógicos e pensar estratégias para garantir que todos tenham possibilidades de participar e aprender, mesclando as diferenças para que de fato a inclusão ocorra.

A inclusão exige que o educador amplie as competências que já possui: observa, investiga, planeja de acordo com o aluno que possui, avalia continuamente seu trabalho, redimensiona o seu planejamento (BATISTA. p.28. 2001.).

O professor carece de aptidões para lidar com as desigualdades, superar suas implicâncias e estar a todo instante ágil para corresponder às novas situações e episódios que podem ocorrer dentro da sala. Dessa forma, diante do aluno surdo, o professor deve entender e ter conhecimento da Língua de Sinais - LIBRAS, para que ele possa conversar contextualizando o ensino com o meio sociocultural do aluno e transmitir os conteúdos ensinados na sala de aula.

Foi comprovada a incapacidade da escola para educar o surdo nos moldes convencionais, devido a sua vocação pra a permanência dos processos pedagógicos, sendo constatado que a Libras é o recurso inicial necessário pra a verdadeira emancipação dos surdos e sua inclusão tanto escolar quanto social (CARVALHO 2007, p.33).

Discorrendo de tal afirmação de Carvalho (2007), fica evidente a importância da LIBRAS no ambiente escolar, bem como a do profissional da educação estar sempre se atualizando com as novas tendências pedagógicas inovando nos conteúdos, buscando sempre o ponto de desequilíbrio do aluno, tirando-o da zona "cômoda", e se especializando para possibilitar o ensino aprendizagem do surdo, pois só assim a escola de fato irá cumprir seu papel de inclusão, já que através da língua haverá aprendizagem. Note-se a importância do professor e da escola para uma educação transformadora na educação do aluno surdo, ter uma educação de qualidade, é primordial para prepará-lo ao mercado de trabalho, para que de fato a inclusão social se consolide.

Inclusão no Mercado de Trabalho: Fomentar sobre inclusão social é indispensável começar do âmbito familiar, e na fase da 
escolarização, para que as pessoas com necessidades especiaisse sintam integrado no mercado de trabalho, para que de fato a inclusão social ocorra, dentro de uma sociedade cada vez mais capitalista e seletiva.Usufruímos na declaração de Salamanca, o artigo dezenove que trata das políticas educacionais na qual, deve ser levado em total consideração as diferenças e situações individuais. Nota-sea importância da Língua Brasileira de Sinais - LIBRAS, como meio essencial de comunicação entre os surdos, por exemplo, deveria ser reconhecido, e com base legal garantir que todas as pessoas surdas tenham acesso a uma escola Bilingue, tendo a LIBRAS, como sua primeira língua. Deste modo, o aluno surdo seria inserido numa escola que respeitasse sua cultura de fato, assim chegaria no mercado de trabalho preparado para diversidades do mundo capitalista, com uma base de ensino sólida no seu desenvolvimento cognitivo.

19. Políticas educacionais deveriam levar em total consideração as diferenças e situações individuais. A importância da linguagem de signos como meio de comunicação entre os surdos, por exemplo, deveria ser reconhecida e provisão deveria ser feita no sentido de garantir que todas as pessoas surdas tenham acesso a educação em sua língua nacional de signos. Devido às necessidades particulares de comunicação dos surdos e das pessoas surdas/cegas, a educação deles pode ser mais adequadamente provida em escolas especiais ou classes especiais e unidades em escolas regulares. (SALAMANCA, 1996).

De acordo com Jesus (2009), a inclusão deve começar primeiramente no âmbito familiar, com a aceitação que existe uma pessoa com certo tipo de necessidade especial,deste modo ela pode minimizar as limitações que poderão encontrar na vida e desta forma expor a sociedade que ela pode modificar sua visão,onde a pessoa com necessidade especial é limitada e incapacitada de serem absorvidaspelo mercado de trabalho, pelo contrário elas podem sim, até serem melhores profissionais do que as demais pessoas. Mesmo com Lei Federal $N^{\circ} 10.436 / 2002$ na qual o reconhece a LIBRAS como uma língua, ainda presenciamos algumas pessoas que dessabemde tal comunicação entre os surdos, em queváriaspartilham que são simples gestos para mostrarem algo que gostariam de manifestar. No mercado de trabalho, muitos ainda se referem ao funcionário surdo de mododifamatória como "mudinho", por não entender a sua necessidade especial menos ainda sua comunicação assim impossibilitando ainda mais a aprendizagem da linguagem para que possa se comunicar com o surdo. No caso do art. 93 da Lei $\mathrm{n}^{\mathrm{o}} 8.213$ de julho de 1991, o ensino básico juntamente com um preparo profissional mais qualificado representa um apoio primordial para a execução da Lei. Nota-se a observância sob várias perspectivas da determinação peculiar a reserva legal de vagas, diante disso para a execução de suas obrigatoriedades é essencial a existência de pessoas qualificadas, com o intuito de não afetar o desenvolvimento do mercado nacional.

A precariedade do modelo brasileiro de ensino lamentavelmenteafeta os mais variadossetores, implicandono desenvolvimentoda Nação como um todo, uma vez que para um progresso amplo de um país requer mão de obra qualificada, e para isto necessita de políticas públicas contundente no setor educacional do país. Não adianta meramenteredigir Leis e aprová-las, se não existir meios que garantam sua eficácia irrestrita perante seus cidadãos Neste modeloemerge a carência da presença do Estado garantidor, o qual de acordo com os conceitos de Gugel tem a obrigação, o dever de proporcionar meios que possibilitem à sociedade a dignidade mencionada nos textos constitucionais.

\section{Considerações Finais}

A partir das revisões bibliográficas que fundamentaram a pesquisa, evidenciou-se um avanço nas Leis brasileiras que amparam o aluno surdo nas escolas do país, como a Constituição Federal do Brasil de 1988, Leis educacionais, entre elas a Lei $n^{\circ} 9.394$ de 1996 conhecida também como Lei de Diretrizes e Bases da Educação Nacional (LDB) e sua inclusão no mercado de trabalho pela Lei Federal $n^{\circ} 8.213$ de julho de 1991. Verificou-se que os direitos constitucionais dos cidadãossurdos e/ou com surdez foram garantidos de certa forma, pois todos podem frequentar as classes de aula do Brasil, e a escola, por seu turno, não pode mais negar a matrícula para pessoas com necessidades especiais, além da participação do mercado de trabalho tanto no setor público quanto no setor privado, Apesar dos avanços conquistados pela comunidade surda, esses constatados em pesquisas, ainda não foram obtidos uma educação inclusiva nas escolas, uma vez que garantiu a matrícula e permanência do aluno com necessidades especiais, porém não o ensino de qualidade. Mesmo com a valorização da LIBRAS e da inclusão do aluno surdo demonstrados em documentos, questiona-se a inclusão dos surdos, visto que as leis, decretos, diretrizes entre outros documentos foram divulgados, mas não implementados na sociedade como um todo. Nota-se que a comunidade escolar, os pais e principalmente a comunidade surda devem permanecer, requerendo seus direitos linguísticos. As escolas necessitam cumprir com exatidão o que preconizaa legislação, a fim de cumpri-la em seu meio sociocultural e acolher os alunos surdos sem maiores restrições, adaptando seu currículo em conformidade com sua necessidade específica dos surdos, com materiais visuais, provas adaptadas para Libras, se possível, formar salas bilíngues e também lugar para a escola bilíngue e permitir o acompanhamento desse aluno por um intérprete na sala de aula regular. $\mathrm{O}$ artigo 93 da Lei $\mathrm{n}^{\mathrm{o}}$ 8.213/91 é imprescindívelo estímulo do sistema de inclusão no Brasil. Entretanto, o mesmo só atingirasua indenidadediante dasimposições do mercado privado, exigidas pelo rígido sistema socioeconômico capitalista, quando a mão de obra com deficiência passar a ser devidamente qualificada. Logo, nesta circunstância, é plausível assegurar que as multas empregadas nas situações de transgressão são impertinentes na ótica defendido por este artigo, pois a não execução das cotas, por muitas vezes é alheio à vontade do empregador.

\section{REFERÊNCIAS}

Diretrizes Operacionais do Atendimento Educacional Especializada na Educação Básica, modalidade Educação Especial. Brasília, 2009.

. Lei de Diretrizes e Bases da Educação Nacional. Lei $\mathrm{N}^{\circ}$ 9.394, 20 de dezembro de 1996. Brasília, Ministério da Educação, 1996. http://www.planalto.gov.br/ccivil_03/leis/L9394.htm Acesso em: 18 jun. 2016.

Lei $\mathrm{N}^{\circ}$ 10.098, Presidência da República, 19 de dezembro de 2000. < http://www.planalto.gov.br/Ccivil_03/LEIS/L10098.htm > Acesso em: 22 jun. 2016. 
Política Nacional de Educação Especial na Perspectiva da Educação Inclusiva. Secretaria de Educação Especial - MEC/SEESP, 2008. Disponível em: Acesso em: 08. mar. 2020.

2002, p. 23.

BAPTISTA, C. R. Inclusão ou exclusão?In: VEIGA-NETO, A.; SCHMIDT, S. (Orgs.). A educação em tempos de globalização. Rio de Janeiro: DP\&A, 2001. p.20-40.

BARBOSA, H. O Desenvolvimento de Conceitos e Procedimentos Numéricos de Crianças Surdas e NãoSurdas de idade Pré-Escolar. Relatório Final de PósDoutorado. CNPq. 2008.

BRASIL. Constituição de 1988. Constituição da República Federativa do Brasil. Brasília, DF: Senado, 1988. $<$ http://www.planalto.gov.br/ccivil_03/Constituicao/Const ituicao.htm> Acesso em: 26 jun. 2016.

CARVALHO, Paulo Vaz de. Breve História dos Surdos no Mundo. SurdUniverso; 2007.

GUGEL, Maria Aparecida, Pessoas com deficiência e o direito ao trabalho. Florianópolis: Obra Jurídica, 2007.

LOBATO, M. J. S. O aluno surdo e o ensino de matemática: desafios e perspectivas na escola regular de ensino em natal, $\quad 2013.2$ Disponível em: $<$ http://www.conferencias.ulbra.br/index. php/ciem/vi/paper/viewFile/815/69 > Acesso em: 30 Set. 2016.

LOPES, Maria da Glória. Jogosnaeducação: criar, fazer, jogar $-4^{\mathrm{a}}$ ed. Ver. São Paulo : Cortez, 2001.
MACHADO. K. da S. A prática da inclusão de alunos com necessidades educativas especiais em classe regular: um estudo de caso com abordagem etnográfica. (Dissertação de Mestrado). Universidade do Estado do Rio de Janeiro, RJ, 2005 no contexto da inclusão de alunos surdos. Revista do Centro de Educação. v. 19,

NUNES T.; MORENO, C. Aninterventionprogram for promotingdeafpupils' achievement in mathematics. JournalofDeafStudiesandDeafEducation, v. 7, n. 2, p. 120-133, 2002.

NUNES, T.; MORENO, C. Ishearingimpairment a cause ofdifficulties in learningmathematics? In: DONLAN, C. (Ed.). The developmentofmathematical skills: studies in developmentalpsychology. Hove, UK: Psychology Press, 1998. p. 227-254.

RABELO, E. H. Textos Matemáticos: produção, interpretação e resolução de problemas.4.ed. ver. E ampl. Petrópolis, RJ: Vozes, 2002.

RECHICO, C. F. \& MAROSTEGA, V. L. (Re) pensando o papel do educador especial

REILY, LuciaHelena. PORTAL PAPIRUS. Estratégias pedagógicas na escola inclusiva, Entrevistado: 2005. Disponível

em: $<$ http://www.papirus.com.br/entrevista_detalhe.aspx?chav e_entrevista $=7>$ Acesso em: 23 Set. 2016

RIBAS, João. Preconceito contra as pessoas com deficiência: as relações que travamos com o mundo. São Paulo: Cortez, 2007.

SASSAKI, R. K. Inclusão: construindo uma sociedade para Todos. 3. ed. Rio de Janeiro, WVA, 1997. 